\title{
The politics of disease
}

\author{
Obesity in historical perspective
}

\section{Megan Warin}

\section{Background}

Scholarship across the humanities and social and life sciences has documented a wide variety of historical, sociocultural and medical attitudes to large bodies, including both positive and negative associations. Obesity has never been a stable or unified category.

\section{Objective}

The aim of this article is to provide an overview of the historical trajectory of obesity as a disease in a Western context.

\section{Discussion}

Discussions about whether obesity should be classified as a disease have been ongoing. Many scholars regard the early Greeks as the first to identify obesity as a disease, and trace changing manifestations of obesity from Classical times through the Middle Ages and Age of Enlightenment to contemporary times. This trajectory of obesity as a disease is contentious, and in light of recent moves to attribute disease status to obesity in Australia, this article outlines the politics and value of classifying obesity as a disease.
IN 2018, the Australian Government's final report from the Senate Select Committee inquiry into the obesity epidemic recommended that obesity be recognised as a disease and added to the list of medical conditions eligible for the Chronic Disease Management scheme. ${ }^{1}$ Almost a decade earlier, the Weighing it up report (2009) recommended obesity be placed on the Medicare Benefits Schedule as a chronic disease requiring an individual management plan. ${ }^{2}$

The question of whether to classify obesity as a disease in and of itself or continue to consider it a risk factor for diseases such as type 2 diabetes has been a topic of heated debate for years. ${ }^{3,4}$ Part of the problem is that 'disease' is a difficult category to define and changes over time and place. To add to the complexity, there are many differing and competing models to explain the causes of obesity: ${ }^{5-7}$ thrifty genotypes, obesogenic behaviour, obesogenic environments and nutrition transition, as well as biocultural models that examine interactions of genetics, environment, behaviour and culture. ${ }^{8}$ Even within the medical field, conceptualisations of obesity differ. For example, Chang and Christakis, in their analysis of medical textbooks from the 1920 s to 2000 , make the observation that although all editions accepted that obesity resulted from an energy imbalance, each edition differed in emphasis, and a model of obesity could change 'quite independently of definitive experimental evidence'. ${ }^{9}$
Despite the lack of consensus as to a common aetiology, in 1997 the World Health Organization's (WHO's) consultation on obesity classified obesity as a disease. ${ }^{10}$ In June 2013 the American Medical Association followed. ${ }^{11,12}$ Clinicians in Canada have recently called for obesity to be conceptualised as a chronic disease such as type 2 diabetes or hypertension in order for patients to qualify for comprehensive medical intervention. There have also been discussions about whether obesity should have been included in the Diagnostic and Statistical Manual of Mental Disorders Fifth Edition $(D S M-V)$ as a mental disorder. ${ }^{13}$ Labelling obesity as a disease is much more than a medical decision and has serious implications for both people and society. It can provide certain benefits and legal privileges but also enforce social norms and entrench stigma. At worst, it can lead to exploitation by commercial interests and apathy from governments to address upstream factors such as inequality that influence health trajectories and outcomes.

\section{Histories of fat, flesh and obesity}

Fatness has always been around - but has not always been called obesity or considered a disease. Historians point to a continuity of obesity across historical times by referring to the ancient Greek philosophers and physics - Aristophanes, Plato, Aristotle, Hippocrates and Galen. ${ }^{14-16}$ But the Greeks were ambivalent 
about fatness, and there were both negative and positive associations of large bodies. Many references to Greek statues show the positive values of curves, especially on women. A series of small statues discovered across Europe from the Paleolithic era is often cited as evidence of obesity in prehistory. One iconic statue is the Venus of Willendorf, a small stone statue dated approximately 24,000 BC that represents a woman with pendulous breasts and abdominal adiposity. A number of similar figurines, all of which are of women, are said to be 'the earliest depictions of obesity' that provide evidence that 'obesity existed during the Paleolithic era'. ${ }^{17}$ Some scholars argue that these statues do not represent obesity but are important fertility symbols that show 'a rare and exaggerated phenomenon', ${ }^{18}$ and may have been related to stylised imaginings of pregnancy. Others suggest they may have been toys, connected to ideas of divinity, wealth, prestige or sexuality. ${ }^{19}$

Galen used common Greek words such as pachus (fat), efsarkos (chubby) and pieira (rich) to describe what we might consider today as obese. These words had multiple meanings and shifted and changed depending on the context in which they were used. ${ }^{19}$ Galen considered some types of fatness as a healthy body form and a 'natural humoral condition', 19 not as a state of illness. However, Galen also identified another form of fatness polisarkos-derived from poli (which means a lot) and sarkos (flesh). This was seen as an 'unnatural state' in humoral medicine as the body was seen as unbalanced. In Galenic physiology, digested food was thought to be converted to blood, and a surplus of blood was thought to cause fatness. Excess blood and fat also led to 'warm temperaments'; when flesh accumulated, the person's temperament was considered wet and warm.

Treatment of polisarkos involved a specific diet, exercise, baths and massage to help make one's temperament dryer. This was not a diet based on calorie reduction as it was not until 1887 that the calorie - describing the energy content of food - began to enter popular and medical discourse in relation to nutrition. ${ }^{20}$ Galen's recommended diet related to balancing of the humours in the body. Recommended foods were based on purgative effects of certain plants and the balance of different humoural properties of foods (such as their drying powers).

Large bodies enjoyed a level of status into the Middle Ages, where noblemen revelled in enormous feasts and endless eating, and prosperity and wealth were demonstrated by the capacity to purchase food in abundance. Women were described as fat, tender and beautiful, and a big person was rarely the object of insult. ${ }^{21}$ As in Classical times, historians note distinct forms of Latin largeness - the power of the pinguis (big) and the prapingus (very big). The very big had difficulty moving, and big men were inept at war. William the Conqueror was described as 'so enormously fat in 1087 that the French King was led to say that the Englishman must be about to give birth'. ${ }^{21}$

These differing accounts of fatness in Classical times and the Middle Ages are often presented as analogous to the modern terms obesity and morbid obesity. However, these studies conflate words such as fat, fatness, flesh, corpulence and gluttony with contemporary understandings of obesity. Hautin, for example, states, 'The women immortalized in Stone Age sculpture were fat; there is no other word for it. Obesity was already a fact of life for palaeolithic man - or at least for palaeolithic women'. ${ }^{22}$ Fatness slides into obesity, but these are not one and the same thing. They have differing statuses and values across history. Moreover, the many cross-cultural examples of fatness (which are not related to health) similarly highlight completely different cultural registers, values and meanings attributed to large bodies. ${ }^{4,23-26}$

The medical term obesity was not used until the 17 th century by Thomas Venner in his book Via Recta (1620), ${ }^{27}$ and mostly in relation to the desire of the Caucasian upper classes to maintain status. Around this time fatness began to be linked to scales of civilisation, with the shame and spectacle of obesity exemplified by the medical 'freak shows' of racialised and gendered fat bodies such as Saartjie Baartman (the so-called Hottentot Venus from South Africa).
In the 18 th and 19 th centuries, the word corpulence was popularised by the English undertaker William Banting in Letter on corpulence, addressed to the public (1863). ${ }^{28}$ In this pamphlet, Banting detailed how a diet of low sugar and starch enabled him to shed weight. So successful was this autobiographical text, people considered Banting as the 'father of dieting' ${ }^{29}$ and speak of 'banting' when trying to lose weight. ${ }^{14}$ Together with industrialisation and the birth of consumer culture, Banting's treatise on the 'crying evil' of corpulence set the stage for fat middle-class people to be denigrated and metaphorically represented as greedy, lazy and corrupt. Overconsumption became linked with obesity and the fat person stood in 'as the symbol par excellence of the sin of [political corruption and] gluttony' ${ }^{29}$

With the rise of global capitalism in the late 19th and early 20th centuries, a preference for slender bodies came to the fore, and all forms of fatness became morally judged and stigmatised; obesity was no longer associated with opulence and wealth, but pathologised as a medical condition. ${ }^{8,14}$ Sets of terms and measurements based on statistical calculations and body weights began to appear, accompanied by universal weight charts. In 1942, the Metropolitan Life Insurance Company made standard tables to identify 'ideal' (and later 'desirable') weight, ${ }^{30-32}$ and with the naming of weight-to-height ratios as the body mass index (BMI) by Keys and colleagues in $1972,{ }^{33}$ obesity was understood as a health risk that required medical intervention. Further refinement of these (imperfect) standard measures of obesity led to formalisation of the BMI in 2000 by the WHO for international monitoring ${ }^{8}$ and, more popularly, for assessment of individual health.

\section{Implications}

Hippocrates and Galen did name some types of fatness as a disease and recommended certain diets and exercise to balance bodily humours. These Classical meanings attributed to fatness and the accompanying remedies were very 
different to contemporary understandings of biomedical bodies and treatments. However, a danger in seeing a continuity of obesity across historical periods lies in the recourse to personal responsibility, where diet and exercise continue to be touted as a key solution.

One of the key findings of the Senate Select Committee inquiry into the obesity epidemic in Australia was that policy and practice approaches that focus on individual responsibility have not worked. New approaches to address obesity are needed. This requires intersectoral co-operation across a range of agencies (including government legislation and regulation) to tackle the many social determinants (such as poverty, housing, employment) that have an impact on people's ability to eat, and to eat well. This also requires great sensitivity to the stigmatisation of fatness and the unintended harms of labelling obesity as a disease.

If obesity becomes a disease, a proportion of the population will be labelled as 'sick', and a range of services, pharmaceuticals and instruments will be produced to manage them. This creates an opportunity for the weight loss industry to put diet medications on the same level as other medical procedures, and for diets and surgical interventions to be paid for through health insurance premiums, thus profiting commercial interests and insurers, not the public. ${ }^{34,35}$ For those who argue that labelling obesity a disease will reduce stigma, there is no indication that such a move will abate the entrenched moral judgements about people who are deemed lazy and gluttonous.

Meanings of fatness and obesity are plural and have changed across history and within and between cultures. Obesity cannot be treated merely as a universal 'medical problem' but rather as a complex set of historical and cultural ideas about the politics of food, gender, sexuality, race and social class. ${ }^{36,37}$ The question, as Allison and colleagues suggest, should not be, 'Is obesity a disease?', but rather, 'Should obesity be considered a disease?' because of the sociocultural, political, ethical and moral aspects involved. ${ }^{38}$

\section{Authors}

Megan Warin PhD, ARC Future Fellow 2015-2019, Professor, School of Social Sciences, The University of Adelaide, Adelaide, SA; Research Leader (Biosocial Approaches to Health), The Robinson Research Institute, The University of Adelaide, Adelaide, SA. megan.warin@adelaide.edu.au

Competing interests: None.

Funding: This project was funded by an Australian Research Council Future Fellowship (Project ID: FT140100825)

Provenance and peer review: Commissioned, externally peer reviewed.

\section{Acknowledgments}

This article has benefited from the exchange of intellectual ideas with Dr Tanya Zivkovic and the @NutrireCoLab, an international organisation of (mainly) anthropologists who engage with obesity, diabetes and social justice.

\section{References}

1. Parliament of Australia. Final report: Obesity epidemic in Australia. Canberra: Commonwealth of Australia, 2018.

2. Standing Committee on Health and Ageing. Weighing it up: Obesity in Australia. Canberra: The Parliament of the Commonwealth of Australia: House of Representatives, 2009.

3. Heshka S, Allison DB. Is obesity a disease? Int J Obes 2001;25(10):1401-04.

4. Warin M, Zivkovic T. Why is obesity such a political issue? In: Fatness, obesity and disadvantage in the Australian suburbs: Unpalatable politics. Switzerland: Palgrave Macmillan, 2019; p. 29-55.

5. Karasu SR. An overview of the complexities in obesity: Limitations and challenges. Am J Lifestyle Med 2013;7(3):192-205. doi: 10.1177/1559827612460832

6. Karasu SR. The obesities: An overview of convergent and divergent paradigms. Am J Lifestyle Med 2014;10(2):84-96. doi: $10.1177 / 1559827614537773$

7. Wells JC. The evolution of human adiposity and obesity: Where did it all go wrong? Dis Model Mech 2012;5(5):595-607. doi: 10.1242/dmm.009613.

8. Ulijaszek SJ. Models of obesity: From ecology to complexity in science and policy. Cambridge: Cambridge University Press, 2017.

9. Chang VW, Christakis NA. Medical modelling of obesity: A transition from action to experience in a 20th century American medical textbook. Sociol Health IIIn 2002;24(2):151-77. doi: 10.1111/14679566.00289 .

10. World Health Organization. Obesity: Preventing and managing the global epidemic. WHO Technical Report Series 894. Geneva: WHO, 1999.

11. American Medical Association. Proceedings of the 2013 Annual Meeting of the American Medical Association. Chicago, IL, USA: AMA, 2013. Available at www.ama-assn.org/sites/ ama-assn.org/files/corp/media-browser/ public/hod/a13-csaph-reports_0.pdf [Accessed 9 September 2019].

12. Stoner L, Cornwall J. Did the American Medical Association make the correct decision classifying obesity as a disease? Australas Med 2014;7(11):462-64. doi: 10.4066/AMJ.2014.2281.

13. Volkow, N, O'Brien CP. Issues for DSM-V: Should obesity be included as a brain disorder? Am J Psychiatry 2007;164(5):708-10. doi: 10.1176/ ajp.2007.164.5.708.
14. Gilman SL. Obesity: The biography. New York: Oxford University Press, 2010.

15. Gilman SL. Fat: A cultural history of obesity. Cambridge: Polity Press, 2008.

16. Papavramidou NS, Papavramidis ST, Christopoulou-Aletra H. Galen on obesity: Etiology, effects, and treatment. World J Surg 2004;28(6):631-35. doi: 10.1007/s00268-0047458-5.

17. Malomo K, Ntlholang O. The evolution of obesity: From evolutionary advantage to a disease. Biomed Res Clin Prac 2018;3(2):1-5. doi: 10.15761/ BRCP.1000163.

18. Haslam D, Rigby N. A long look at obesity. Lancet 2010;376(9735):85-86.

19. Hill SE. Eating to excess: The meaning of gluttony and the fat body in the ancient world. Santa Barbara, CA: Praeger, 2011.

20. Hargrove JL. History of the calorie in nutrition. Journal Nutr 2006;136(12):2957-61. doi: 10.1093/ jn/136.12.2957.

21. Vigarello $G$. The metamorphoses of fat: A history of obesity. Delogu CJ, translator. New York: Columbia University Press, 2013.

22. Hautin RJR. A historical framework for the development of ideas about obesity. In: Bray GA, Bouchard C, editors. Handbook of Obesity: Etiology and Pathophysiology. New York: Marcel Dekker, 2004.

23. Popenoe R. Feeding desire: Fatness, beauty and sexuality among a Saharan people. London: Routledge, 2004.

24. Yates-Doerr E. The weight of obesity: Hunger and global health in postwar Guatemala. Oakland, CA: University of California Press, 2015.

25. Hardin J. Christianity, fat talk, and Samoan pastors: Rethinking the fat-positive-fat-stigma framework. Fat Studies 2015;4(2):178-96. doi: 10.1080/21604851.2015.1015924.

26. Renzaho AMN, Green J, Smith BJ, Polonsky M. Exploring factors influencing childhood obesity prevention among migrant communities in Victoria, Australia: A qualitative study. J Immigr Minor Health 2018;20(4):865-83. doi: 10.1007/ s10903-017-0620-6.

27. Venner T. Via recta ad vitam longam. London: Printed by Edward Griffin for Richard Moore, 1620

28. Banting W. Letter on corpulence, addressed to the public [pamphlet]. Kensington 1863.

29. Farrell A. Fat shame: Stigma and the fat body in American culture. New York: New York University, 2011.

30. Metropolitan Life Insurance Company. Ideal weights for men. Statistical Bulletin-Metropolitan Life Insurance Company 1942;23:6-8.

31. Metropolitan Life Insurance Company. Ideal weights for women. Statistical BulletinMetropolitan Life Insurance Company 1943;24:6-8.

32. Metropolitan Life Insurance Company. New weight standards for men and women. Statistical Bulletin-Metropolitan Life Insurance Company 1959;40:1-10.4.

33. Keys A, Fidanza F, Karvonen MJ, Kimura N, Taylor HL. Indices of relative weight and obesity. J Chronic Dis 1972;25(6):329-43.

34. Oliver JE. The politics of pathology: How obesity became an epidemic disease. Perspect Biol Med 2006;49(4):611-27. doi: 10.1353/ pbm.2006.0062.

35. Katz DL. Perspective: Obesity is not a disease. Nature 2014;508(7496):S57. doi: 10.1038/508S57a. 
36. Stearns PN. Fat history: Bodies and beauty in the modern west. New York: New York University Press, 1997.

37. Schwartz H. Never satisfied: A cultural history of diets, fantasies and fats. New York: Free Press, 1986.

38. Allison DB, Downey M, Atkinson RL, et al. Obesity as a disease: A white paper on evidence and arguments commissioned by the Council of the Obesity Society. Obesity (Silver Spring) 2008; 16(6):1161-77. doi: 10.1038/oby.2008.231. 